\title{
The Isolated Sixth Gelsolin-Repeat and Headpiece Domain of Villin Bundle F-actin in the Presence of Calcium and are Linked by a 40- Residue Unstructured Sequence ,t,
}

\author{
Serge L. Smirnov, Nancy G. Isern§, Zhenghui G. Jiang, David W. Hoyt $§$, and C. James \\ McKnight \\ Department of Physiology and Biophysics, Boston University School of Medicine, 715 Albany Street, \\ Boston, Massachusetts 02118
}

$\S H i g h$ Field Magnetic Resonance Facility, WR Wiley Environmental Molecular Sciences Laboratory, High Field NMR Facility, P.O. Box 999, K8-98 Richland, Washington 99352

\begin{abstract}
Villin is an F-actin regulating, modular protein with a gelsolin-like core and a distinct C-terminal 'headpiece' domain. Localized in the microvilli of the absorptive epithelium, villin can bundle Factin and, at higher calcium concentration, is capable of a gelsolin-like F-actin severing. The headpiece domain can, in isolation, bind F-actin and is crucial for F-actin bundling by villin. While the three-dimensional structure of the isolated headpiece is known, its conformation in the context of attachment to the villin core remains unexplored. Furthermore, the dynamics of the linkage of headpiece to the core has not been determined. To address these issues, we employ a 208 residue modular fragment of villin, D6-HP, which consists of the sixth gelsolin-like domain of villin (D6) and the headpiece (HP). We demonstrate that this protein fragment requires calcium for structural stability and, surprisingly, is capable of $\mathrm{Ca}^{2+}$-dependent F-actin bundling, suggesting that D6 contains a cryptic F-actin binding site. NMR resonance assignments and ${ }^{15} \mathrm{~N}$-relaxation measurements of D6-HP in $5 \mathrm{mM} \mathrm{Ca}^{2+}$ demonstrate that D6-HP consists of two independent structural domains (D6 and HP) connected by an unfolded 40-residue linker sequence. The headpiece domain in D6-HP retains its structure and interacts with D6 domain only through the linker sequence without engaging in other interactions. Chemical shift values indicate essentially the same secondary structure elements for the D6 domain in D6-HP as in the highly homologous gelsolin domain 6. Thus, the headpiece domain of villin is structurally and functionally independent from the core domain.
\end{abstract}

\section{Keywords}

Villin; headpiece; F-actin; actin-bundling; gelsolin-like domains; NMR; ${ }^{15} \mathrm{~N}$ relaxation; dynamics; order parameters; modular protein

\footnotetext{
${ }^{\dagger}$ This work was supported by National Institutes of Health Grant GM062886 to C.J.M.

${ }^{*}$ The ${ }^{1} \mathrm{H},{ }^{15} \mathrm{~N}$, and ${ }^{13} \mathrm{C}$ NMR assignments and R1, R2 and heteroneuclear NOE values for the D6-HP sample reported here have been deposited to the Biological Magnetic Resonance Data Bank (BMRB accession number 15097).

*To whom correspondence should be addressed. E-mail: cjmck@bu.edu. Telephone: (617) 638-4042. Fax: (617) 638-4041.

Supporting Information Available

The supporting information consists of electron micrographs that demonstrate that isolated villin headpiece does not bundle F-actin filaments. This material is available free of charge via the Internet at http://pubs.acs.org
} 
Villin is a major cytoskeletal protein involved in the upkeep of actin bundles supporting microvilli in the brush-border membrane of the absorptive epithelium cells of the intestine and kidney (1). The capacity of villin to organize filamentous actin (F-actin) into tight bundles in vitro and to bind efficiently to F-actin explains its ability to induce microvilli formation in cultured cells (2). However, an additional and, perhaps, crucial role of villin may be the catabolism of microvilli after injury (3).

High sequence homology and similar proteolytic cleavage patterns relate villin to gelsolin, an F-actin severing and capping predecessor of a number of cytoskeleton regulating proteins (1). The amino acid sequence of villin consists of two distinct parts, the larger $\mathrm{N}$-terminal gelsolinlike 'core' and the C-terminal 'headpiece' domain (Figure 1). Proteolysis, in vitro, demonstrates that F-actin bundling by villin requires both the core and headpiece domain (4).

The villin 'core' shares $\sim 50 \%$ sequence identity with gelsolin and displays the typical gelsolinlike 6-fold internal homologous repeat pattern $(5,6,7)$. The distinct sequence of the villin headpiece domain is $50 \%$ identical to other headpiece domains, including those of quail (8), supervillin (9) and dematin (10). The headpiece is unrelated to any other protein sequence in the Genbank database. Like most other headpiece domains, the 76 residue villin headpiece folds independently into a compact structure and retains its full F-actin-binding activity in isolation $(4,11,12)$. In spite of the high sequence identity between gelsolin and villin "core", their domains are not interchangeable. For example, a chimera protein consisting of the three $\mathrm{N}$-terminal villin core domains, three $\mathrm{C}$-terminal gelsolin domains and villin headpiece does not induce villin-like F-actin assemblies in vivo (13).

Direct structural information about villin is limited to the three-dimensional solution structure of domain one $(14,15)$ and the headpiece domain $(16)$ determined by NMR spectroscopy. The structure of the domain one (14T) is similar to other gelsolin-like domains with a five-stranded $\beta$-sheet sandwiched between helices (15). Based on the three-dimensional structure of a villin headpiece construct missing the first 9 residues (HP67), we proposed a model for the F-actin binding surface on HP67 (16). This model was further refined and corroborated by functional and structural studies $(17,18)$.

Like many actin remodeling proteins of the gelsolin superfamily, villin is regulated by environmental signals, including calcium. Villin links actin filaments into bundles at physiological levels of $\mathrm{Ca}^{2+}$, whereas it caps and severs F-actin at higher $\mathrm{Ca}^{2+}$ concentrations (1). Calcium binding sites were proposed to be located in villin core domains 1 (14), 4 and 6 (19). Interestingly, the C-terminal half of villin, a fragment referred to as 51T (20), binds Gactin in a calcium-dependent fashion. The F-actin binding activity (11) and three-dimensional structure of the isolated headpiece is not calcium-dependent.

The crystal structure of villin has not been reported and no structural data on modular fragments of villin is available. Additionally, no structural data exist on modular protein fragments containing headpiece domains. In contrast to villin, there is a wealth of structural information on gelsolin modular fragments including the crystal structures of the calcium-free complete protein (21) and calcium-bound C-terminal half of gelsolin (22). The latter structure clearly shows that gelsolin domains 5 and 6 (G5 and G6) each have a single calcium ion bound to their surfaces.

Although the isolated villin headpiece domain has been under intense scrutiny, its properties in the context of the core domains still remain untested. Here we present a structural and functional study of D6-HP (Figure 1), the first modular villin fragment containing the headpiece (HP) attached to the sixth core domain (D6). We use heteronuclear NMR spectroscopy to characterize the structure of D6-HP and electron microscopy to assay its F-actin bundling. We 
utilize this villin fragment in order to determine whether the headpiece remains an independently folded domain retaining its structure and F-actin binding property, or is altered through interactions with the core. The flexibility and the length of the core-to-headpiece linker sequence is also a major focus of our study. Because the D6 domain of villin is proposed to contain a $\mathrm{Ca}^{2+}$-binding site, our study also targets the role of calcium in regulation of the D6HP fragment.

We find that for stability of the folded, monomeric form of D6-HP, calcium is required in millimolar concentrations. We demonstrate that the D6-HP fragment consists of two structured domains, D6 and HP, separated by an unfolded linker sequence. The D6-HP calcium binding site is clearly associated with the D6 domain, which shares $\sim 50 \%$ sequence identity with the domain 6 of gelsolin (G6) that also binds calcium. In the context of the core domain D6, headpiece retains its three-dimensional structure. The 40-residue linker sequence is likely the longest inter-domain connector in villin or gelsolin, suggesting the role of villin headpiece as an independently acting domain. Our data indicate that the secondary structure of D6-HP corresponds to that of gelsolin domain G6 and the isolated headpiece. Surprisingly, we find that D6-HP bundles F-actin in the presence of high levels of calcium, suggesting an F-actin binding site on domain D6.

\section{Materials and methods}

\section{Construction of the pD6-HP expression vector}

The D6-HP fragment was designed to include the C-terminal 208 residues of chicken villin including core domain 6, the linker sequence and headpiece domain (Figure 1). The construct was cloned from full-length chicken villin cDNA (a gift of Dr. Paul Matsudaira, Whitehead Institute/M.I.T.) into the pET-24a vector (Novagen) using standard protocols (23). To produce the plasmid pD6-HP, PCR was used to amplify the designed sequence with primers containing an Nde I site at the $5^{\prime}$ end and a Hind III site at the $3^{\prime}$ end of the ATG stop codon.

\section{Protein sample preparation}

D6-HP was over-expressed from the pD6-HP plasmid in Escherichia coli line BL21(DE3) (Novagen). After growth at $37^{\circ} \mathrm{C}$ in Luria Broth medium to an OD600 of $\sim 0.6$, the cells were harvested by centrifugation at $5000 \mathrm{~g}$ for $30 \mathrm{~min}$, washed in $1 \mathrm{~L}$ of the M9T medium, reharvested and transferred to ${ }^{13} \mathrm{C} /{ }^{15} \mathrm{~N}$-labeled M9T medium for expression (24). The cells were equilibrated in the labeled M9T medium for 1 hour, induced by $0.8 \mathrm{mM}$ Isopropyl $\beta$-D-1thiogalactopyranoside (IPTG) and harvested after 4 hours by centrifugation at $5000 \mathrm{~g}$ for 30 min. The following lysis and gel-filtration steps were performed in A-buffer: $50 \mathrm{mM} \mathrm{NaCl}, 5$ $\mathrm{mM}$ dithiothreitol (DTT), $0.01 \% \mathrm{NaN}_{3}, 20 \mathrm{mM}$ sodium phosphate buffer at $\mathrm{pH}$ 7.0. The cells were lysed in A-buffer by sonication in the presence of DNAseI $(1 \mu \mathrm{g} / \mathrm{ml})$, DTT $(50 \mathrm{mM})$ and lysozyme $(50 \mu \mathrm{g} / \mathrm{ml})$. Cell debris was removed by centrifugation at $200,000 \mathrm{~g}$ for $40 \mathrm{~min}$. The supernatant was applied to a Sephadex G50 column $(2 \times 100 \mathrm{~cm})$ run in A-buffer at a rate of $0.5 \mathrm{ml} / \mathrm{min}$. The D6-HP-containing fractions were combined and loaded onto HiTrap ${ }^{\mathrm{TM}} \mathrm{SP}$ HP and HiTrap ${ }^{\mathrm{TM}} \mathrm{Q}$ HP (GE Healthcare) columns $(1 \mathrm{ml})$ connected to each other and equilibrated in $50 \mathrm{mM}$ Piperazine-1,4-bis(2-ethanesulfonic acid) (PIPES), $\mathrm{pH} 7.0,50 \mathrm{mM} \mathrm{NaCl}, 5 \mathrm{mM}$ $\mathrm{CaCl}_{2}$. The flow-through that contained D6-HP protein free of DNA was collected at a flowrate $1 \mathrm{ml} / \mathrm{min}$ and analyzed using SDS-PAGE which revealed greater than $95 \%$ protein purity. Finally, the sample was concentrated and PIPES buffer replaced with d18-PIPES with a 10 kDa MW cutoff Amicon Ultra-4 concentrator (Millipore). Protein concentrations were determined by UV absorbance at $280 \mathrm{~nm}$ (25). The polypeptide identity was confirmed by mass spectrometry (Dana Farber Cancer Institute, Molecular Biology Core Facility). 


\section{F-actin bundling by D6-HP}

Actin was purified from chicken pectoral muscle using standard procedures (26) and was first incubated in F-buffer (10 mM TRIS at $\mathrm{pH} 8.0,1 \mathrm{mM} \mathrm{MgCl}_{2}, 100 \mathrm{mM} \mathrm{NaCl}, 0.1 \mathrm{mM}$ ATP, $0.2 \mathrm{mM}$ DTT, $3 \mathrm{mM} \mathrm{NaN}_{3}$, and $0.1 \mathrm{mM} \mathrm{CaCl}_{2}$ ) overnight to allow polymerization. Purified D6-HP, $1.1 \mathrm{mM}$ in $5 \mathrm{mM} \mathrm{Ca}^{2+}$, was used as the source of D6-HP for the bundling assay. This D6-HP stock solution was diluted $\sim 220$-fold to yield a final concentration of $5 \mu \mathrm{M}$ and was incubated with F-actin at 2:1, 1:1 and 1:2 molar ratios in F-buffer, either with or without the addition of $5 \mathrm{mM} \mathrm{CaCl}_{2}$, for $45 \mathrm{~min}$ at $4^{\circ} \mathrm{C}$. Control F-actin and the F-actin/D6-HP mixtures were loaded on a carbon-coated and glow-discharged copper grid (SPI Supplies) for $1 \mathrm{~min}$, washed with 10 drops buffer containing $5 \mathrm{mM}$ Tris, $50 \mathrm{mM}$ sodium chloride at $\mathrm{pH} 7.5$, and then stained with $1 \%$ uranyl acetate (27). All samples were imaged on a Philips CM12 transmission electron microscope operating at $120 \mathrm{kV}$ with a $\mathrm{LaB}_{6}$ filament and recorded on SO-163 EM (Kodak) film at 45,000 $\times$ magnification under minimal electron dose conditions. The film was processed with undiluted Kodak D-19 developer for 12 min and Kodak rapid fixer for $5 \mathrm{~min}$. Electron micrographs were digitized on a Creo IQ Smart2 Scanner (Global Imaging) at $1270 \mathrm{dpi}$.

\section{NMR data collection and processing}

The NMR samples consisted of $1.1 \mathrm{mM}$ D6-HP, $10 \%{ }^{2} \mathrm{H}_{2} \mathrm{O}, 5 \mathrm{mM} \mathrm{CaCl}_{2}, 10 \mathrm{mM}$ d10-DTT, $0.01 \% \mathrm{NaN}_{3}, 20 \mathrm{mM}$ d18-PIPES ( $\mathrm{pH} 7.0$ ). The $\mathrm{pH}$ was adjusted with no correction for the effect of ${ }^{2} \mathrm{H}_{2} \mathrm{O} .2 \mathrm{D}$ - and 3D-NMR data collection was performed at $25^{\circ} \mathrm{C}$ on a Bruker AVANCE II $800 \mathrm{MHz}$ spectrometer equipped with a Cryoprobe located at the Brandeis University NMR facility, and two spectrometers at Pacific Northwest National Laboratory's High Field Magnetic Resonance Facility, a Varian INOVA $750 \mathrm{MHz}$ spectrometer with a room temperature probe and a Varian Inova $600 \mathrm{MHz}$ spectrometer outfitted with a cryoprobe. Processing of the NMR data was performed utilizing the nmrPipe software (28).

The ${ }^{15} \mathrm{~N}$ HSQC spectrum of the isolated headpiece domain (HP67) was recorded at $25^{\circ} \mathrm{C}$ on a Bruker DMX $500 \mathrm{MHz}$ spectrometer at the Boston University Core Facility for Structural NMR. The assignment of the backbone ${ }^{1} \mathrm{H}$ and ${ }^{15} \mathrm{~N}$ resonances of $\mathrm{HP} 67$ at $25^{\circ} \mathrm{C}$ was performed by matching the cross-peaks to those published for $\mathrm{HP} 67$ sample at $20^{\circ} \mathrm{C}$ (BMRB entry 4428 ).

\section{NMR resonance assignment}

The backbone resonance $\left({ }^{1} \mathrm{H},{ }^{15} \mathrm{~N},{ }^{13} \mathrm{C}\right)$ assignment of the D6-HP sample was performed through a combined investigation of $2 \mathrm{D}{ }^{15} \mathrm{~N}$ HSQC $(29,30)$ and the following 3D NMR datasets: HNCA (31), HN(CO)CA (31), HNCACB (32,33), CBCA(CO)NH (34), HNCO (31), HN(CA)CO (35), HNHA (36), HNHB (37), HBHA(CO)NH (38). The side-chain resonances (aliphatic ${ }^{1} \mathrm{H}$ and ${ }^{13} \mathrm{C}$ ) assignments were obtained from HCCH-COSY (39), CC (CO)NH (40) and $\mathrm{HC}(\mathrm{CO}) \mathrm{NH}(40) \mathrm{NMR}$ data. Aromatic side-chain ${ }^{1} \mathrm{H}$ assignments were derived from dedicated heteronuclear $2 \mathrm{D}$ experiments (41). The visualization and analysis of the NMR spectra and the cross-peak picking was performed with the NMRDRAW (28) and NMRVIEW (42) software. Chemical shifts for all nuclei are relative to the internal standard 3-(trimethylsilyl) tetradeutero sodium propionate (43).

\section{NMR relaxation measurements and order parameter computations}

${ }^{15} \mathrm{~N}$ relaxation measurements were performed on a $750 \mathrm{MHz}$ spectrometer using $2 \mathrm{D}$ protondetected heteronuclear NMR experiments based on those of Farrow, et. al. 1994. The R1relaxation rates were extracted from a series of spectra with relaxation delays of 100, 200, 300, $400,600,800,1000,1500$ and $2000 \mathrm{msec}$. The R2 rates were derived from experiments with relaxation delays of $10,20,30,50,70,100,130,170,210$ and $250 \mathrm{~ms}$. The heteronuclear $\left\{{ }^{1} \mathrm{H}-{ }^{15} \mathrm{~N}\right\}-\mathrm{NOE}$ experiments were recorded with a proton saturation time of $2.5 \mathrm{sec}$ 
(NOEpresat) and without the presaturation (NOEnopresat). The $\left\{{ }^{1} \mathrm{H}_{-}{ }^{15} \mathrm{~N}\right\}-\mathrm{NOE}$ values were calculated as NOEpresat/NOEnopresat ratio.

The R1, R2 and $\left\{{ }^{1} \mathrm{H}-{ }^{15} \mathrm{~N}\right\}-\mathrm{NOE}$ values were determined by fitting the data intensities to exponentials using the routines in NMRVIEW (42). The Lipari-and-Szabo model-free order parameter $S^{2}$ (44) was calculated by the FAST-Modelfree program (45), a user-friendly interface to the Modelfree $(46,47)$ software. Out of the total 176 assigned ${ }^{15} \mathrm{~N}$ HSQC backbone cross-peaks, 144 were included into the relaxation and $\left\{{ }^{1} \mathrm{H}_{-}{ }^{15} \mathrm{~N}\right\}-\mathrm{NOE}$ analysis. The remaining 32 resonances were excluded due to their low intensities or significant overlap with other crosspeaks.

\section{Secondary structure elements detection}

The secondary structure content of the D6-HP fragment was predicted by the TALOS (48) software based on the backbone ${ }^{1} \mathrm{H}_{\alpha},{ }^{15} \mathrm{~N},{ }^{13} \mathrm{C}_{\alpha},{ }^{13} \mathrm{CO}$ and side-chain ${ }^{13} \mathrm{C}_{\beta}$ chemical shift values. The standard TALOS reference protein set of three-dimensional structures and resonances was used. This set did not include the isolated headpiece domain HP67 (16) or gelsolin-like domains.

\section{Results}

\section{Calcium is required for stability and folding of the monomeric form of D6-HP}

As described in the Materials and Methods, the D6-HP polypeptide was labeled with ${ }^{15} \mathrm{~N}$ and ${ }^{13} \mathrm{C}$ isotopes by expression in bacteria. The purification of the protein sample included gel filtration and ion-exchange chromatography steps. Preliminary NMR data and gel filtration chromatography showed that D6-HP aggregates within hours (Figure 2A). The protein elutes in two major peaks (I and III) and one minor peak (II). The elution volume of peak I was consistent with a monomeric species, whereas peaks II and III indicated D6-HP oligomers. In NMR ${ }^{15} \mathrm{~N}$ HSQC spectra (not shown), there were fewer resonances than expected and many broad peaks at random coil chemical shifts, a pattern indicating a significant fraction of unfolded structure and/or protein aggregation. Notably, the set of cross-peaks characteristic of the isolated headpiece domain (HP67) was clearly present. Alterations of temperature, $\mathrm{pH}$ and $\mathrm{NaCl}$ level did not prevent the aggregation. However, the long-term stability of the monomeric form of the D6-HP was achieved by inclusion of calcium in concentrations greater than $1 \mathrm{mM}$ (Figure 2B). Therefore, we collected all the NMR data for D6-HP protein in the presence of 5 $\mathrm{mM} \mathrm{Ca}^{2+}$.

The ${ }^{15} \mathrm{~N}-\mathrm{HSQC}$ spectrum of $1.1 \mathrm{mM}$ D6-HP recorded at $25^{\circ} \mathrm{C}$, pH 7.0 in $5 \mathrm{mM} \mathrm{Ca}^{2+}$ (Figure $3 \mathrm{~A}$ ) indicates a folded, monomeric protein sample. The cross-peaks are sharp and their number corresponds to that expected from the amino acid composition of the D6-HP sequence. The effect of calcium concentration on the spectra was sampled from $5 \mathrm{mM}$ to $50 \mathrm{mM}$. There were no changes in the observed ${ }^{15} \mathrm{~N}$ HSQC spectra. This suggests saturation of all available $\mathrm{Ca}^{2+}$ binding sites in D6-HP by $5 \mathrm{mM}$ calcium.

\section{The headpiece domain retains its three-dimensional structure in D6-HP}

We utilized the heteronuclear 3D NMR data recorded with a ${ }^{13} \mathrm{C} /{ }^{15} \mathrm{~N}$-labeled D6-HP sample to assign the backbone resonances $\left({ }^{1} \mathrm{HN},{ }^{15} \mathrm{~N},{ }^{13} \mathrm{C}_{\alpha}\right.$ and $\left.{ }^{13} \mathrm{CO}\right)$ for 176 residues of the 208 in D6-HP using established procedures (49). Utilizing side-chain-sensitive 3D NMR

experiments, the side-chain resonances were identified for 191 residues ( $92 \%$ of the sequence) including some of those without backbone assignments. Out of the seventeen residues for which no assignments are available, six are positioned on either the extreme $\mathrm{N}$ - or C-terminus of the sequence. All other eleven unassigned residues are located between positions 60 and 85 (Figure 5). Out of these eleven residues, three are prolines. The five-residue sequence (68 to 72) 
constitutes the longest continuous stretch of unassigned residues, suggesting a loop undergoing intermediate exchange. All the stretches of unassigned amino acids are flanked by residues whose ${ }^{15} \mathrm{~N}-\mathrm{HSQC}$ signals are weak or missing, suggesting those regions are in the intermediate structural exchange on the NMR time scale.

The ${ }^{15} \mathrm{~N}$ HSQC pattern of the isolated headpiece domain (16) corresponds well with the ${ }^{15} \mathrm{~N}$ HSQC spectrum of D6-HP (Figure 3A): Each HP67 cross-peak directly overlaps with, or is positioned very closely to, the corresponding D6-HP resonance. Most of the ${ }^{1} \mathrm{HN}$ and ${ }^{15} \mathrm{NH}$ chemical shift differences (Figure 3B) are negligible $\left(<0.04 \mathrm{ppm}\right.$ for ${ }^{1} \mathrm{HN}$ and $<0.2 \mathrm{ppm}$ for ${ }^{15} \mathrm{NH}$ ), indicating very similar structural environments for the headpiece domain in D6-HP and HP67. The six N-terminal residues of HP67 display noticeable differences in chemical shift which can be attributed to the effect of the linker sequence of D6-HP influencing the Nterminal residues of the HP domain. One residue in the middle of the headpiece sequence, D166, displays a significantly higher than average ${ }^{1} \mathrm{HN}$ chemical shift difference, $0.15 \mathrm{ppm}$, between D6-HP and HP67 samples (Figure 3B).

\section{D6-HP consists of two structured domains, D6 and HP, separated by an unfolded linker sequence}

The ${ }^{15} \mathrm{~N}$ backbone relaxation rates R1 and R2 as well as the $\left\{{ }^{1} \mathrm{H}_{-}{ }^{15} \mathrm{~N}\right\}-\mathrm{NOE}$ (Figure $4 \mathrm{~A}, \mathrm{~B}, \mathrm{C}$ ) indicate three distinct structural entities within D6-HP, namely two structured regions, positions 1-105 and 145-206, and a disordered sequence in between. The order parameters $\left(S^{2}\right)$ from the Lipari-and-Szabo model-free analysis (44) (Figure 4D) follow the same trend.

In agreement with the NMR relaxation data, the backbone ${ }^{1} \mathrm{HN}$ chemical shift profile (Figure 4E) indicates two regions, 1-105 and 145-206, with well dispersed values indicative of a folded polypeptide. The linker sequence, positions $105-145$, is characterized by the ${ }^{1} \mathrm{HN}$ chemical shift values narrowly clustered between $8.0-8.5 \mathrm{ppm}$ consistent with a random coil, unfolded polypeptide. The ${ }^{1} \mathrm{H}_{\alpha}$ chemical shift profile has a similar pattern (not shown).

The 15N-HSQC spectrum (Figure 3A) clearly shows an uneven distribution of the intensities of the D6-HP cross-peaks. The strongest cross-peaks belong to residues in the D6-to-HP linker (residues 104-144), the weakest are from the D6 domain, and those from the HP domain are of intermediate intensity. This observation is consistent with the relative $\mathrm{R} 2$ relaxation rates (Figure 4B). The linker residues are nearly unrestrained, resulting in slower $\mathrm{R} 2$ relaxation rates and hence their higher 15N-HSQC intensity. On the other hand, the residues of the largest domain, D6, relax the fastest, and thus their HSQC cross-peaks are the weakest. The resonances of the HP domain, which is structured but significantly smaller than D6, displays intermediate HSQC peak intensities.

The large error bars in the $\left\{{ }^{1} \mathrm{H}^{-15} \mathrm{~N}\right\}$-NOE plot in the area of the linker are due to the generally low intensities of the NOE cross-peaks for these residues, which may be attributable to exchange of the backbone amides with water. Residue Phe84, in the D6 domain, stands out due to its low $\mathrm{R} 2$ rate and low $\left\{{ }^{1} \mathrm{H}_{-}{ }^{15} \mathrm{~N}\right\}$-NOE ratio value (Figure $4 \mathrm{~B}, \mathrm{C}$ ). Additionally, the Lipari-and-Szabo model-free analysis marked Phe84 as 'unassigned'. It should be noted here, that the NMR resonances of the residue following Phe84 remain unassigned, possibly due to the intermediate exchange of this region of the sequence.

\section{The D6-HP secondary structure corresponds to that of gelsolin domain 6 and the isolated headpiece}

Protein chemical shift values, especially ${ }^{1} \mathrm{H}_{\alpha},{ }^{15} \mathrm{NH},{ }^{13} \mathrm{C}_{\alpha},{ }^{13} \mathrm{CO}$ and ${ }^{13} \mathrm{C}_{\beta}$, are good indicators of the secondary structure patterns. We employed the TALOS software (48) to predict the secondary structure elements in D6-HP using our chemical shift assignments. The secondary 
structure of D6-HP corresponds closely to that of domain 6 (G6) in the crystal structures of calcium-bound (22) or calcium-free gelsolin (21) and isolated villin headpiece, HP67, (17) (Figure 5). The only major exception is the $\mathrm{C}$-terminal helix of calcium-free gelsolin, which does not have a homologous counterpart in the $\mathrm{Ca}^{2+}$-bound D6-HP. The C-terminal helix of gelsolin is not visible in the calcium-bound crystal structure (22).

\section{Calcium binds to the D6 domain}

The ${ }^{15} \mathrm{~N}$ HSQC spectrum of D6-HP in the absence of calcium was compared to that in the presence of $5 \mathrm{mM}$ calcium. 96 D6-HP backbone amide resonances in a calcium-free HSQC spectrum were reliably assigned by comparison with the HSQC recorded in $5 \mathrm{mM}$ calcium. They include $33{ }^{1} \mathrm{HN}$ resonances in the D6 sequence, 27 in the linker and 36 in the HP domain. Without calcium, one quarter of all the D6 backbone amide resonances either disappear or have significant changes in their chemical shift values. The presence of calcium affects the first 80 residues of D6, suggesting that calcium binding is important for the folding this entire region.. The remaining C-terminal part of D6 (positions 81-105), linker region and HP domain are insensitive to calcium.

These data indicate that in the absence of calcium the headpiece domain remains structurally independent from the core D6 domain. All the most prominent changes in the D6-HP theedimensional structure caused by the lack of calcium are associated with the core domain D6, not the headpiece or the linker region.

\section{D6-HP bundles F-actin in a calcium-sensitive fashion}

Villin is an F-actin bundling protein. Previous work (2) indicated that the N-terminal half of villin (core domains 1,2,3) and the headpiece represent the two F-actin binding sites required for F-actin bundling by villin. We confirmed that the D6-HP construct was still active with respect to actin binding using F-actin sedimentation assays (not shown). We also examined Factin filaments decorated with D6-HP by negative stain electron microscopy. Surprisingly, we found that D6-HP organizes F-actin into bundles (Figure 6). We tested F-actin bundling by the D6-HP villin fragment at two levels of calcium: $5 \mathrm{mM}$ and $0.1 \mathrm{mM}$ and at the D6-HP to Gactin molar ratio values of 1:2, 1:1 and 2:1. In all the experiments, the incubation time was 45 min, significantly shorter than the time required for D6-HP aggregation at sub-millimolar calcium concentrations. This way, we ensured that any absence of F-actin bundling by D6-HP is not due to the aggregation of D6-HP. At $5 \mathrm{mM}$ calcium, D6-HP bundles F-actin at any D6HP to G-actin molar ratio (Figure 6D). Without D6-HP, no F-actin bundling was observed at either level of calcium (Figure 6A and 6B). The D6-HP cannot bundle F-actin in low $(0.1 \mathrm{mM})$ calcium (Figure 6C). This suggests that the $\mathrm{Ca}^{2+}$-induced conformational change is essential for the cryptic F-actin binding site in D6-HP and further suggests that this actin binding site is in the D6 portion of the construct.

\section{Discussion}

\section{Villin headpiece in the context of the core domains}

Our study of D6-HP protein is the first structural and dynamic characterization of a modular fragment of villin containing both a region of the core and the C-terminal headpiece domain. We envisioned two possible regimes for the villin headpiece: one in which it is tethered to the core by a flexible linker sequence and functions independently from the adjacent core domain and the other in which the headpiece and domain 6 of the core engage in strong steric interactions.

The results of our study clearly demonstrate that the headpiece retains its structure and is connected to the adjacent core domain D6 by a long, unstructured linker sequence. Therefore, 
the wealth of previous data $(11,16)$ describing the properties and mode of interaction of headpiece with F-actin applies to headpiece in the context of attachment to the core domain. In addition to this fundamental result, our study highlights several surprising findings and poses new questions discussed below.

\section{D6-HP bundles F-actin by utilizing a cryptic F-actin binding site on D6}

Villin is a modular protein which consists of the N-terminal gelsolin-like six-domain core and the C-terminal headpiece domain. Villin is a multifunctional actin accessory protein, whose activity is regulated by several environmental messengers, including calcium. At physiological levels of calcium, villin bundles actin, whereas at higher calcium levels villin can, like gelsolin, sever and cap actin filaments. Villin bundles F-actin by utilizing two F-actin binding sites, one in the C-terminal headpiece domain and the other at the $\mathrm{N}$-terminus of the gelsolin-like core of villin $(2,11)$. The isolated headpiece is capable of calcium-independent F-acting binding (11) and does not bundle filaments with or without calcium (data not shown).

Surprisingly, we find that D6-HP fragment is capable of bundling F-actin in the presence of 5 $\mathrm{mM}$ calcium (Figure 6). Domains 2-3 have been shown to be the F-actin binding site in the core domain of villin (11). Because in D6-HP the headpiece retains its 'isolated' fold, is structurally independent from domain D6, and has only one F-actin binding site, we propose that villin core domain D6 has a cryptic, calcium-dependent F-actin binding site that is revealed when the domain is excised from the rest of the gelsolin-like core.

\section{The fold and calcium binding of D6 domain resemble those of gelsolin domain G6}

The high sequence identity between villin and gelsolin and the secondary structure similarity between D6 and the gelsolin core domain 6 (G6) (Figure 5) suggest that the fold of D6 will likely be very similar to that of G6. Thus, we propose that villin domain D6 folds as fivestranded $\beta$-sheet sandwiched between the long $\alpha$-helix and a shorter helical region in the $\mathrm{C}$ terminal sequence of the domain. This fold is typical for the gelsolin-like core domains whose structures are known $(15,22,50)$.

Our data indicate that, in the absence of calcium, the first $~ 80$ residues of D6-HP change their fold or are destabilized as compared to the D6-HP structure in high calcium. Without sufficient calcium in solution, D6-HP cannot bundle F-actin (Figure 6) and aggregates over the course of several hours. This suggests that calcium binding may play a vital role in regulating villin through a binding site located within the first 80 residues of D6. The location of this calciumbinding site on domain D6 is different from the two sites on the surface of domain 1 of villin (14T), which were predicted to reside around residues 92 and 121 respectively (14).

Based on the sequence and secondary structure similarity to gelsolin domain G6, we propose villin residues Asn647, Asp648 and Glu670 (D6-HP residues Asn29, Asp30 and Glu52 respectively) as the likely calcium-binding site on the surface of D6 domain of villin. Two of these residues, Asp648 and Glu670, bind calcium via their side chains in the calcium-bound gelsolin structure (22) and are absolutely conserved in villin and gelsolin sequences. The third residue, Asn647, lends its backbone carbonyl oxygen to bind calcium and this position varies between villin and gelsolin and among different species.

\section{Unstructured regions of D6 domain}

The chemical shift values, R1, R2 and $\left\{{ }^{1} \mathrm{H}^{1}{ }^{15} \mathrm{~N}\right\}$-NOE data (Figure 4) indicate two structured domains in the D6-HP sequence, D6 and HP. Nevertheless, the NMR relaxation and assignment data suggest that some D6 residues are unstructured. 
Seventeen residues in the D6-HP sequence remain unassigned (Figure 5). Four of them are positioned at the $\mathrm{N}$-terminus and two at the $\mathrm{C}$-terminus. All internal unassigned residues are located within positions 60-85 of domain D6. The longest unassigned stretch in D6 includes five residues from Pro68 to Asp72. Because this region corresponds to the solvent-exposed loop in the crystal structure of the G6 domain of gelsolin (22), we propose that these residues are involved in intermediate structural exchange which weakens their NMR resonances. The second longest stretch of unassigned residues, Ala60-Gln61-Glu62, corresponds to an internal region of the longest helix of G6 in the gelsolin crystal structures. Why these D6-HP residues could not be assigned remains unclear.

Residue Phe84 in the D6 domain appears to be unstructured as manifested by its low R2 value (Figure $4 \mathrm{C}$ ) and the $\left\{{ }^{1} \mathrm{H}_{-}{ }^{15} \mathrm{~N}\right\}-\mathrm{NOE}$ ratio well below 0.6 (Figure $4 \mathrm{C}$ ). In fact, the next residue, Glu85, is unassigned because the residue appears to be involved in structural exchange. In the gelsolin crystal structure, Phe84 and Glu85 correspond to a short unstructured loop on the solvent-exposed surface. Notably, the Phe84 residue is positioned close to the border between the $\mathrm{Ca}^{2+}$-sensitive and $\mathrm{Ca}^{2+}$-insensitive parts of the D6 domain.

\section{The core-to-headpiece linker sequence is the longest inter-domain region in villin}

Our data indicate that the unstructured linker sequence connecting the structured domains D6 and HP consist of approximately 40 residues (positions 105-145) which are exposed to solvent (Figure 4). This core-to-headpiece linker sequence is likely the longest villin inter-domain connector because it is significantly longer than any inter-domain region in the gelsolin core (all under 20 residues). Sequence alignments (not shown) indicate that the length of the villin core-to-HP linker sequence varies by only few residues among species. The sequence identity in the villin core-to-headpiece linker region is about $15 \%$, significantly lower than in the D6 and HP domains where sequence identity is close to $50 \%$. Therefore, we conclude that the sequence connecting the gelsolin-like core of villin and the headpiece domain acts purely as an unstructured tether and is unlikely to be a recognition target for specific protein-protein interactions. These properties of the core-to-headpiece linker region of villin correlate well with the proposed role of the villin headpiece as a domain structurally independent from the gelsolin-like core and crucial for the functionality of villin.

\section{The headpiece retains its structure}

Our assignment for the NMR chemical shift values in the headpiece region of D6-HP are very close to those reported for the isolated headpiece, HP67. With the exception of several Nterminal residues of the HP67 sequence close to the linker sequence, most of the headpiece ${ }^{1} \mathrm{H}$ resonances in D6-HP differ from those in HP67 by less that $0.02 \mathrm{ppm}$. One D6HP headpiece residue, D166, displays a significant difference $(0.15 \mathrm{ppm})$ from the corresponding ${ }^{1} \mathrm{H}$ value for the isolated headpiece. This difference cannot be attributed to calcium, because the D166 backbone amide resonates at the same chemical shift in the presence and absence of calcium ions (not shown). Therefore, we expect to observe a slight structural alteration in the area of this residue in D6-HP as compared to the solution structure of the isolated headpiece.

\section{Conclusions}

Our study poses a number of new questions. The most important of them is why the core-toheadpiece linker in villin is so long. Stretched out completely, the 40-residue linker spans $\sim 120 \AA$, greater than the long axis of the folded calcium-free gelsolin $(\sim 100 \AA)$. Is the linker designed to allow the headpiece interact with other core domains of villin? Does the long linker allow for more efficient F-actin bundling by villin? Is the interaction of the villin headpiece domain with the core calcium-sensitive? Future NMR studies and structural simulations of the complete villin in varying conditions will help to clarify this issue. 
Our investigation highlights the role of calcium in structural and functional regulation of villin core domain 6 linked to the headpiece. The work presented in this article prepares the ground for the determination of the solution structure of D6-HP protein and for study of site-specific effects of calcium on the structure of this modular fragment of villin. Such an investigation will provide valuable insights into the functional and structural regulation of villin, a modular, calcium-sensitive, multi-purpose F-actin regulating protein.

\section{Supplementary Material}

Refer to Web version on PubMed Central for supplementary material.

\section{Acknowledgements}

We acknowledge Mehul Dalal for construction of the pD6-HP expression vector and Jeffrey W. Brown for providing actin. We thank Olga Platonova for help in optimizing the purification procedure of the D6-HP sample. Elizabeth Luna provided valuable and greatly appreciated discussion of this work. We are grateful to Donna Baldisseri of Bruker Biospin Inc. (Billerica, MA) for the generous help in collecting preliminary NMR data. The assistance of Susan Pochapsky was instrumental in collecting NMR spectra at the NIH-initiated regional NMR Center at Brandeis University. A portion of the research described in this paper was performed in the High Field Magnetic Resonance Facility of the Environmental Molecular Sciences Laboratory, a national scientific user facility sponsored by the Department of Energy's Office of Biological and Environmental Research and located at Pacific Northwest National Laboratory.

\section{Abbreviations}

DTT, Dithiothreitol; F-actin, filamentous actin; G-actin, monomeric globular actin; IPTG, Isopropyl $\beta$-D-1-thiogalactopyranoside; NOE, Nuclear Overhauser Effect; PIPES, Piperazine-1,4-bis(2-ethanesulfonic acid).

\section{References}

1. Bretscher A, Weber K. Villin is a major protein of the microvillus cytoskeleton which binds both $\mathrm{G}$ and $\mathrm{F}$ actin in a calcium-dependent manner. Cell 1980;20:839-847. [PubMed: 6893424]

2. Friederich E, Vancompernolle K, Louvard D, Vandekerckhove J. Villin function in the organization of the actin cytoskeleton. Correlation of in vivo effects to its biochemical activities in vitro. J Biol Chem 1999;274:26751-26760. [PubMed: 10480879]

3. Ferrary E, Cohen-Tannoudji M, Pehau-Arnaudet G, Lapillonne A, Athman R, Ruiz T, Boulouha L, El Marjou F, Doye A, Fontaine JJ, Antony C, Babinet C, Louvard D, Jaisser F, Robine S. In vivo, villin is required for $\mathrm{Ca}(2+)$-dependent $\mathrm{F}$-actin disruption in intestinal brush borders. J Cell Biol 1999;146:819-830. [PubMed: 10459016]

4. Glenney JR Jr. Weber K. Calcium control of microfilaments: uncoupling of the F-actin-severing and -bundling activity of villin by limited proteolysis in vitro. Proc Natl Acad Sci U S A 1981;78:28102814. [PubMed: 7019912]

5. Kwiatkowski DJ, Stossel TP, Orkin SH, Mole JE, Colten HR, Yin HL. Plasma and cytoplasmic gelsolins are encoded by a single gene and contain a duplicated actin-binding domain. Nature 1986;323:455-458. [PubMed: 3020431]

6. Bazari WL, Matsudaira P, Wallek M, Smeal T, Jakes R, Ahmed Y. Villin sequence and peptide map identify six homologous domains. Proc Natl Acad Sci U S A 1988;85:4986-4990. [PubMed: 2839826]

7. Matsudaira P, Janmey P. Pieces in the actin-severing protein puzzle. Cell 1988;54:139-140. [PubMed: 2839297]

8. Mahajan-Miklos S, Cooley L. The villin-like protein encoded by the Drosophila quail gene is required for actin bundle assembly during oogenesis. Cell 1994;78:291-301. [PubMed: 8044841]

9. Pestonjamasp KN, Pope RK, Wulfkuhle JD, Luna EJ. Supervillin (p205): A novel membraneassociated, F-actin-binding protein in the villin/gelsolin superfamily. J Cell Biol 1997;139:1255-1269. [PubMed: 9382871] 
10. Rana AP, Ruff P, Maalouf GJ, Speicher DW, Chishti AH. Cloning of human erythroid dematin reveals another member of the villin family. Proc Natl Acad Sci U S A 1993;90:6651-6655. [PubMed: 8341682]

11. Pope B, Way M, Matsudaira PT, Weeds A. Characterisation of the F-actin binding domains of villin: classification of F-actin binding proteins into two groups according to their binding sites on actin. FEBS Lett 1994;338:58-62. [PubMed: 8307157]

12. Azim AC, Knoll JH, Beggs AH, Chishti AH. Isoform cloning, actin binding, and chromosomal localization of human erythroid dematin, a member of the villin superfamily. J Biol Chem 1995;270:17407-17413. [PubMed: 7615546]

13. Finidori J, Friederich E, Kwiatkowski DJ, Louvard D. In vivo analysis of functional domains from villin and gelsolin. J Cell Biol 1992;116:1145-1155. [PubMed: 1310994]

14. Markus MA, Nakayama T, Matsudaira P, Wagner G. Solution structure of villin 14T, a domain conserved among actin-severing proteins. Protein Sci 1994;3:70-81. [PubMed: 8142900]

15. Markus MA, Matsudaira P, Wagner G. Refined structure of villin $14 \mathrm{~T}$ and a detailed comparison with other actin-severing domains. Protein Sci 1997;6:1197-1209. [PubMed: 9194180]

16. Vardar D, Buckley DA, Frank BS, McKnight CJ. NMR structure of an F-actin-binding "headpiece" motif from villin. J Mol Biol 1999;294:1299-1310. [PubMed: 10600386]

17. Meng J, Vardar D, Wang Y, Guo HC, Head JF, McKnight CJ. High-resolution crystal structures of villin headpiece and mutants with reduced F-actin binding activity. Biochemistry 2005;44:1196311973. [PubMed: 16142894]

18. Vermeulen W, Vanhaesebrouck P, Van Troys M, Verschueren M, Fant F, Goethals M, Ampe C, Martins JC, Borremans FA. Solution structures of the C-terminal headpiece subdomains of human villin and advillin, evaluation of headpiece F-actin-binding requirements. Protein Sci 2004;13:12761287. [PubMed: 15096633]

19. Kumar N, Khurana S. Identification of a functional switch for actin severing by cytoskeletal proteins. J Biol Chem 2004;279:24915-24918. [PubMed: 15084600]

20. Janmey PA, Matsudaira PT. Functional comparison of villin and gelsolin. Effects of $\mathrm{Ca} 2+, \mathrm{KCl}$, and polyphosphoinositides. J Biol Chem 1988;263:16738-16743. [PubMed: 2846546]

21. Burtnick LD, Koepf EK, Grimes J, Jones EY, Stuart DI, McLaughlin PJ, Robinson RC. The crystal structure of plasma gelsolin: implications for actin severing, capping, and nucleation. Cell 1997;90:661-670. [PubMed: 9288746]

22. Kolappan S, Gooch JT, Weeds AG, McLaughlin PJ. Gelsolin domains 4-6 in active, actin-free conformation identifies sites of regulatory calcium ions. J Mol Biol 2003;329:85-92. [PubMed: 12742020]

23. Sambrook, J.; Fritsch, EF.; Maniatis, T. Molecular Cloning: A Laboratory Manual. Cold Spring Harbor Laboratory Press; 1989.

24. Marley J, Lu M, Bracken C. A method for efficient isotopic labeling of recombinant proteins. J Biomol NMR 2001;20:71-75. [PubMed: 11430757]

25. Edelhoch H. Spectroscopic determination of tryptophan and tyrosine in proteins. Biochemistry 1967;6:1948-1954. [PubMed: 6049437]

26. Pardee JD, Spudich JA. Purification of muscle actin. Methods Enzymol 1982;85(Pt B):164-181. [PubMed: 7121269]

27. Harris, JR.; Horne, RW. Negative staining. In: JR, H., editor. Electron Microscopy in Biology. IRL Press; Oxford, UK: 1991. p. 203-228.

28. Delaglio F, Grzesiek S, Vuister GW, Zhu G, Pfeifer J, Bax A. NMRPipe: a multidimensional spectral processing system based on UNIX pipes. J Biomol NMR 1995;6:277-293. [PubMed: 8520220]

29. Palmer AG, Cavanagh J, Wright PE, Rance M. Sensitivity improvement in proton-detected twodimensional heteronuclear correlation NMR spectroscopy. J. Magn. Reson 1991;93:151-170.

30. Kay LE, Keifer P, Saarinen T. Pure absorption gradient enhanced heteronuclear single quantum correlation spectroscopy with improved sensitivity. J. Am. Chem. Soc 1992;114:10663-10665.

31. Grzesiek S, Bax A. Improved 3D triple-resonance NMR techniques applied to a $31 \mathrm{kDa}$ protein. J. Magn. Reson 1992;96:432-440. 
32. Wittekind M, Mueller L. HNCACB, a High-Sensitivity 3D NMR Experiment to Correlate AmideProton and Nitrogen Resonances with the Alpha- and Beta-Carbon Resonances in Proteins. J. Magn. Reson. B 1993;101:201-205.

33. Muhandiram DR, Kay LE. Gradient-Enhanced Triple-Resonance Three-Dimensional NMR Experiments with Improved Sensitivity. J. Magn. Reson. B 1994;103:203-216.

34. Grzesiek S, Bax A. Correlating backbone amide and side chain resonances in larger proteins by multiple relayed triple resonance NMR. J. Am. Chem. Soc 1992;114:6291-6293.

35. Yamazaki T, Lee W, Arrowsmith CH, Muhandiram DR, Kay LE. A Suite of Triple Resonance NMR Experiments for the Backbone Assignment of 15N, 13C, 2H Labeled Proteins with High Sensitivity. J. Am. Chem. Soc 1994;116(26):11655-11666.

36. Vuister GW, Bax A. Quantitative J correlation: a new approach for measuring homonuclear threebond J(HNH.alpha.) coupling constants in 15N-enriched proteins. J. Am. Chem. Soc 1993;115(17): 7772-7777.

37. Archer SJ, Ikura M, Torchia DA, Bax A. An alternative 3D NMR technique for correlating backbone $15 \mathrm{~N}$ with side chain H $\beta$ resonances in larger proteins. J. Magn. Reson 1991;95:636-641.

38. Grzesiek S, Bax A. Amino acid type determination in the sequential assignment procedure of uniformly 13C/15N-enriched proteins. J. Biomol. NMR 1993;3:185-204. [PubMed: 8477186]

39. Clore GM, Bax A, Driscoll PC, Wingfield PT, Gronenborn AM. Assignment of the side-chain $1 \mathrm{H}$ and 13C resonances of interleukin-1 beta using double- and triple-resonance heteronuclear threedimensional NMR spectroscopy. Biochemistry 1990;29(35):8172-8184. [PubMed: 2261471]

40. Grzesiek S, Anglister J, Bax A. Correlation of Backbone Amide and Aliphatic Side-Chain Resonances in 13C/15N-Enriched Proteins by Isotropic Mixing of 13C Magnetization. J. Magn. Reson. B 1993;101:114-119.

41. Yamazaki T, Forman-Kay JD, Kay LE. Two-Dimensional NMR Experiments for Correlating 13CB and 1Hd/e Chemical Shifts of Aromatic Residues in 13C-Labeled Proteins via Scalar Couplings. J. Am. Chem. SOC 1993;115:11054-11055.

42. Johnson BA, Blevins RA. NMRView: A computer program for the visualization and analysis of NMR data. J Biomol NMR 1994;4:603-614.

43. Wishart DS, Bigam CG, Yao J, Abildgaard F, Dyson HJ, Oldfield E, Markley JL, Sykes BD. 1H, $13 \mathrm{C}$ and $15 \mathrm{~N}$ chemical shift referencing in biomolecular NMR. J Biomol NMR 1995;6:135-140. [PubMed: 8589602]

44. Lipari G, Szabo A. Effect of librational motion on fluorescence depolarization and nuclear magnetic resonance relaxation in macromolecules and membranes. Biophys J 1980;30:489-506. [PubMed: 7260284]

45. Cole R, Loria JP. FAST-Modelfree: a program for rapid automated analysis of solution NMR spinrelaxation data. J Biomol NMR 2003;26:203-213. [PubMed: 12766418]

46. Mandel AM, Akke M, Palmer AG 3rd. Backbone dynamics of Escherichia coli ribonuclease HI: correlations with structure and function in an active enzyme. J Mol Biol 1995;246:144-163. [PubMed: 7531772]

47. Palmer AG, Rance M, Wright PE. Intramolecular motions of a zinc finger DNA-binding domain from Xfin characterized by proton-detected natural abundance 13C heteronuclear NMR spectroscopy. J. Am. Chem. Soc 1991;113:4371-4380.

48. Cornilescu G, Delaglio F, Bax A. Protein backbone angle restraints from searching a database for chemical shift and sequence homology. J Biomol NMR 1999;13:289-302. [PubMed: 10212987]

49. Cavanagh, J.; Fairbrother, WJ.; Palmer, AG.; Skelton, NJ. Protein NMR Spectroscopy: Principles and Practice. Academic Press; 1996.

50. Schnuchel A, Wiltscheck R, Eichinger L, Schleicher M, Holak TA. Structure of severin domain 2 in solution. J Mol Biol 1995;247:21-27. [PubMed: 7897658] 


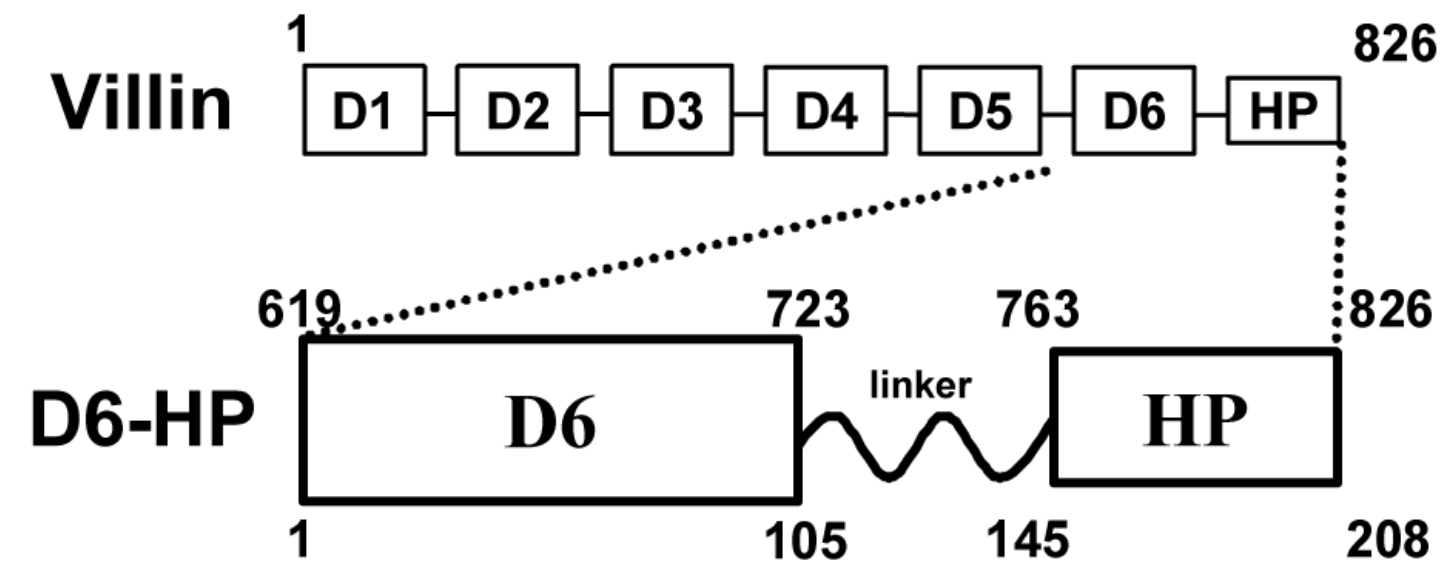

Figure 1.

Cartoon representation of villin and the $23 \mathrm{kDa}$ D6-HP construct. The villin sequence consists of six gelsolin-like repeat (D1-D6) that compose the gelsolin-like 'core' and the C-terminal 'headpiece' domain (HP). The D6-HP modular villin fragment includes the last gelsolin-like repeat (D6), the linking sequence and the headpiece (HP). The numbers on top of the D6-HP drawing correspond to the positions in the chicken villin sequence (1). Numbers on the bottom specify the same positions in the D6-HP construct and are used by default throughout this publication. For the amino acid sequence of D6-HP refer to Figure 5. 

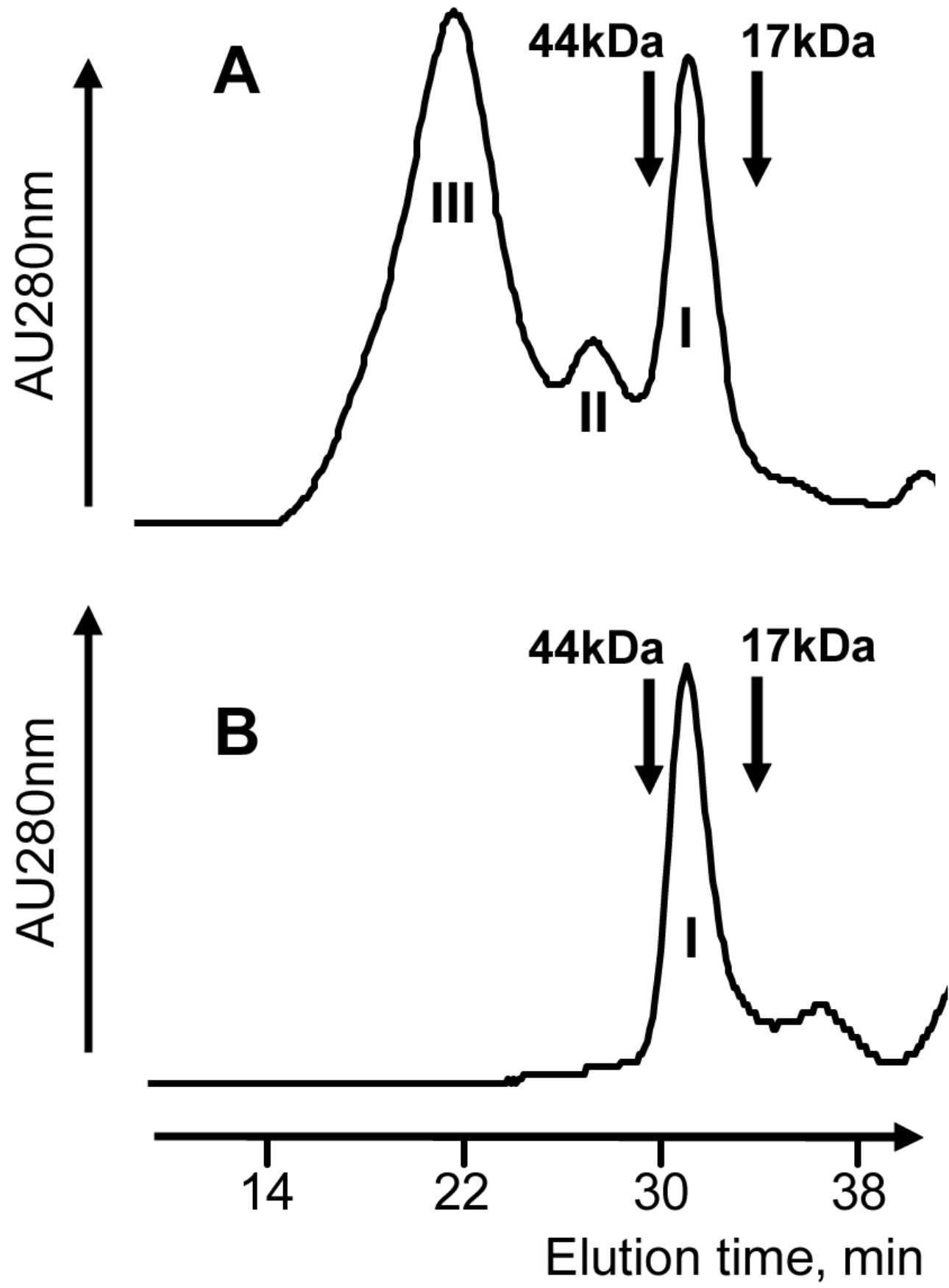

Figure 2.

$\mathrm{Ca}^{2+}$ dependence of the aggregation state of D6-HP. A) D6-HP in gel-filtration buffer and B) D6-HP in gel-filtration buffer and $5 \mathrm{mM} \mathrm{Ca}^{2+}$. I: elution peak of the monomeric D6-HP. II, III: elution peaks of D6-HP aggregates. Arrows indicate the positions of 44 and $17 \mathrm{kDa}$ molecular weight standards, run separately, (Biorad). $100 \mu \mathrm{l}$ of $1.5 \mathrm{mM}$ D6-HP was run in a Superdex GL-200 column (Amersham) in gel-filtration buffer (10 mM Tris, $150 \mathrm{mM} \mathrm{NaCl}, 5$ $\mathrm{mM}$ DTT, $\mathrm{pH} 7.5$ ) with a flow-rate of $0.5 \mathrm{ml} / \mathrm{min}$ at $4^{\circ} \mathrm{C}$. 


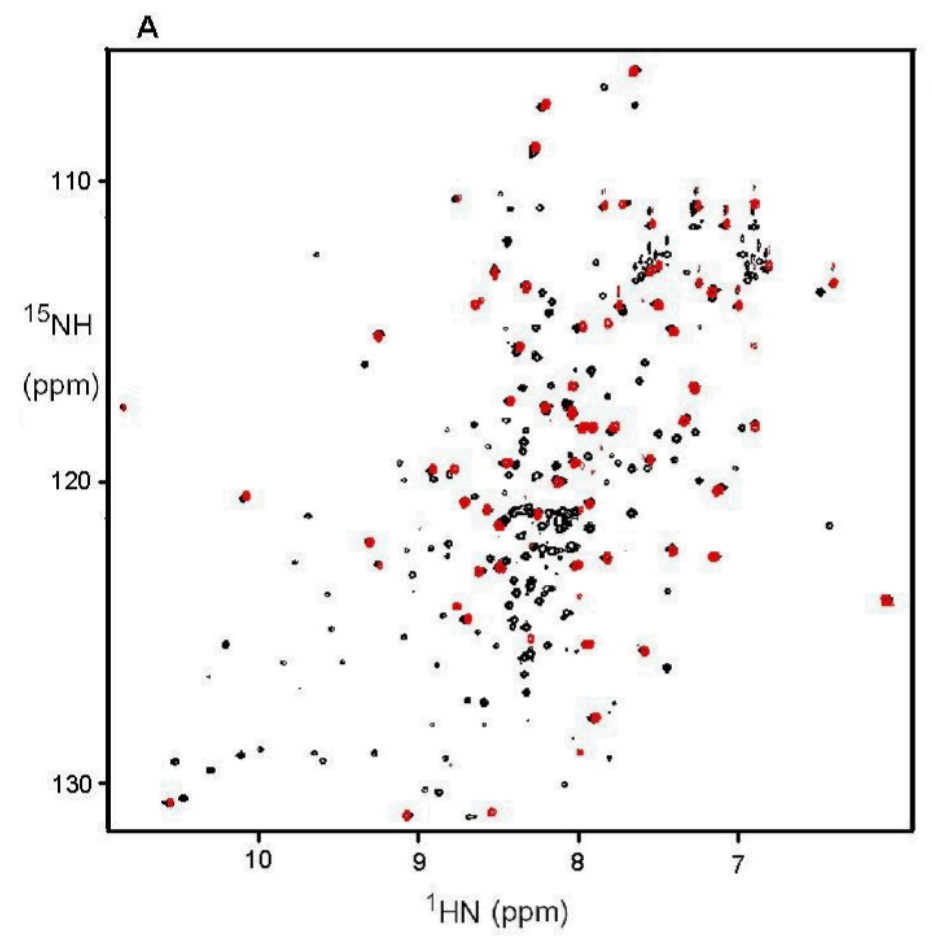

B

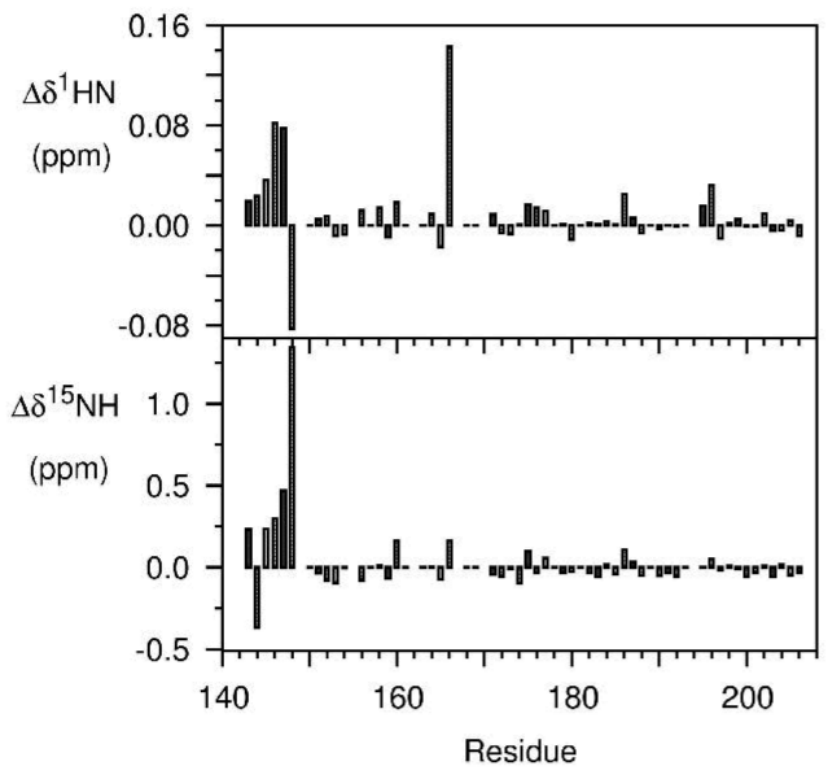

Figure 3.

NMR characterization of D6-HP and comparison with the isolated headpiece (HP67). A) ${ }^{15} \mathrm{~N}-$ HSQC spectra of D6-HP in $5 \mathrm{mM} \mathrm{Ca}^{2+}$ acquired at $800 \mathrm{MHz}$ (black) and isolated headpiece, $\mathrm{HP67}$, acquired at $500 \mathrm{MHz}$ (red), both at $25^{\circ} \mathrm{C}, \mathrm{pH} 7.0$. B) The profile of the backbone ${ }^{1} \mathrm{HN}$ and ${ }^{15} \mathrm{~N}$ chemical shift differences in the headpiece sequence between D6-HP and HP67 samples at $25^{\circ} \mathrm{C}, \mathrm{pH} 7.0$. 


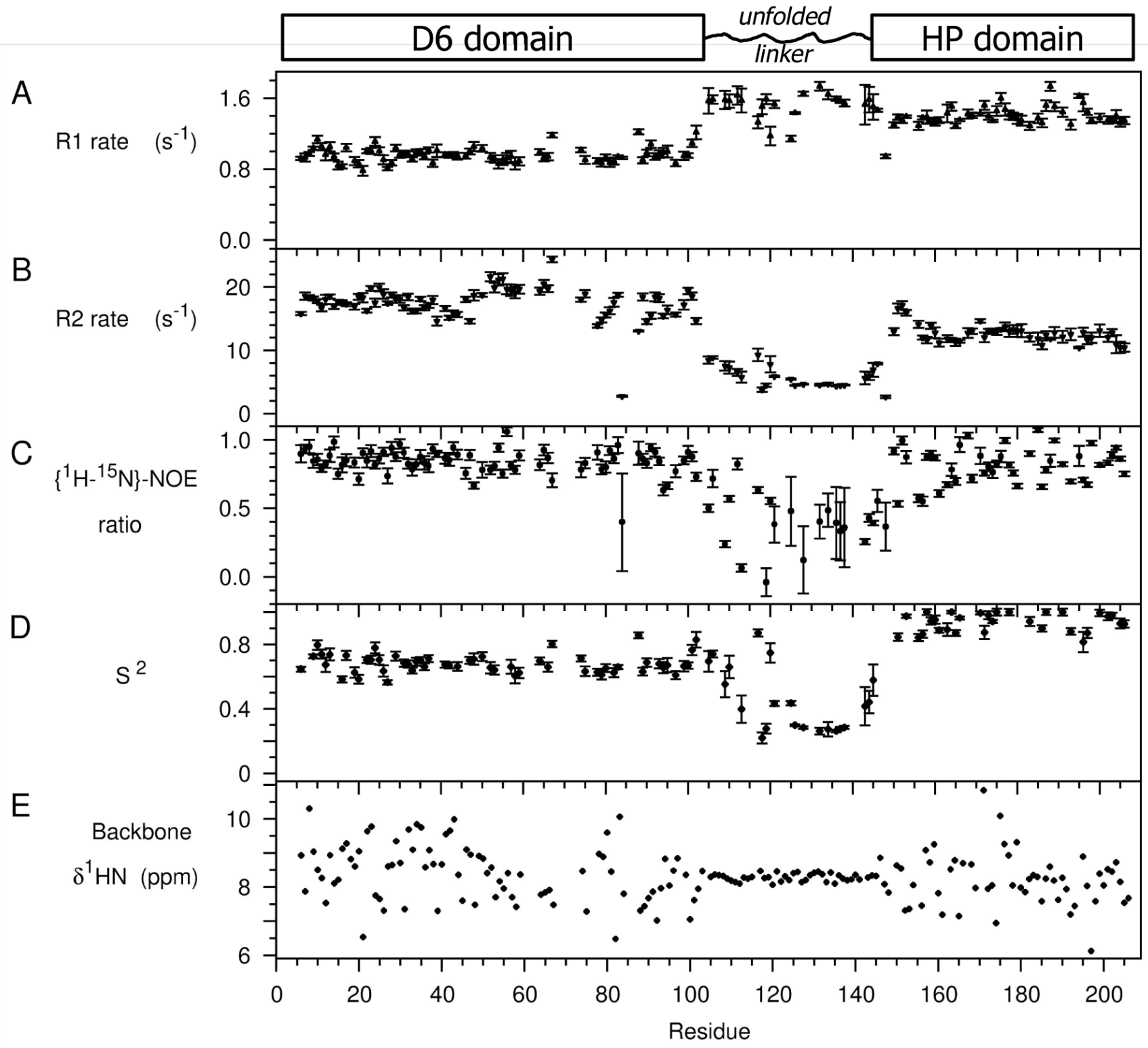

Figure 4.

Relaxation rates, $\left\{{ }^{1} \mathrm{H}-{ }^{15} \mathrm{~N}\right\}$-NOE ratio, order parameter and backbone ${ }^{1} \mathrm{HN}$ chemical shift values for D6-HP. A) R1 rates; B) R2 rates; C) $\left\{{ }^{1} \mathrm{H}_{-}{ }^{15} \mathrm{~N}\right\}-\mathrm{NOE}$ ratio; D) Lipari-Szabo modelfree order parameter, $\mathrm{S}^{2}$, computed with FAST-Modelfree (45); E) backbone ${ }^{1} \mathrm{HN}$ chemical shift values. The domain structure of D6-HP derived from the presented data is displayed on top of the figure. 


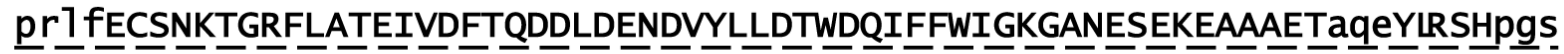

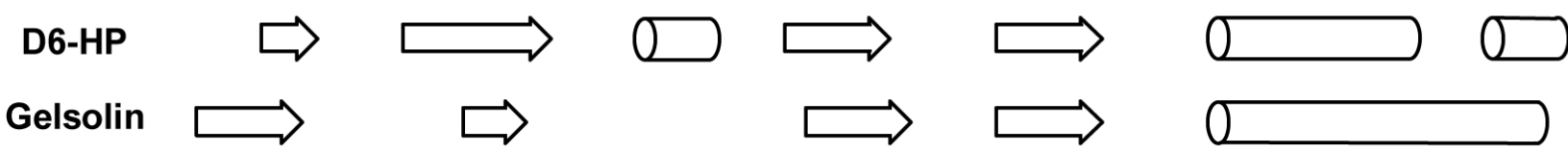

71

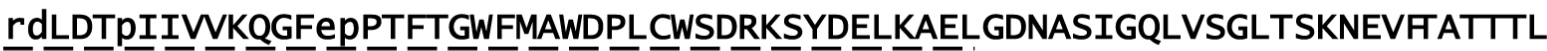

D6-HP

Gelsolin

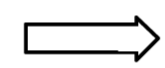

141
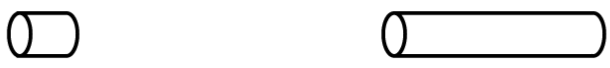

VPTKLETFPLDVLVNTAAEDLPRGVDPSRKENHLSDEDFKAVFGMTRSAFANLPLWKQQNLKKKKG1f

D6-HP
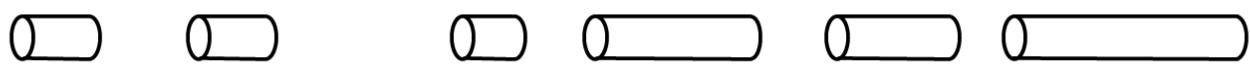

HP67
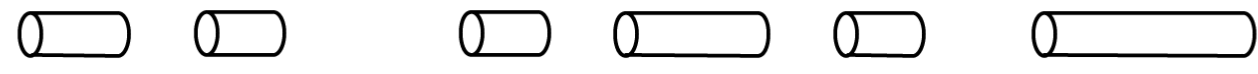

Figure 5.

Comparison of the secondary structure of gelsolin, HP67 and D6-HP. The D6-HP sequence is underlined as follows: 50\% identical to the gelsolin G6 domain (dashed underline), linker sequence (no underline) and villin headpiece (dotted underline).. Secondary structure elements (cylinders represent helices, arrows represent $\beta$-sheets) of D6-HP, as predicted by the TALOS software (48) are mapped onto D6-HP sequence. Secondary structure elements found in the crystal structures of the calcium-free gelsolin G6 domain and the isolated villin headpiece, HP67, are labeled "Gelsolin" and "HP67" respectively. Residues in D6-HP for which no resonance assignments are available are denoted in lowercase. 


\section{$0.1 \mathrm{mM} \mathrm{Ca}^{2+}$}

\section{F-actin}

\section{F-actin $+$ D6-HP}

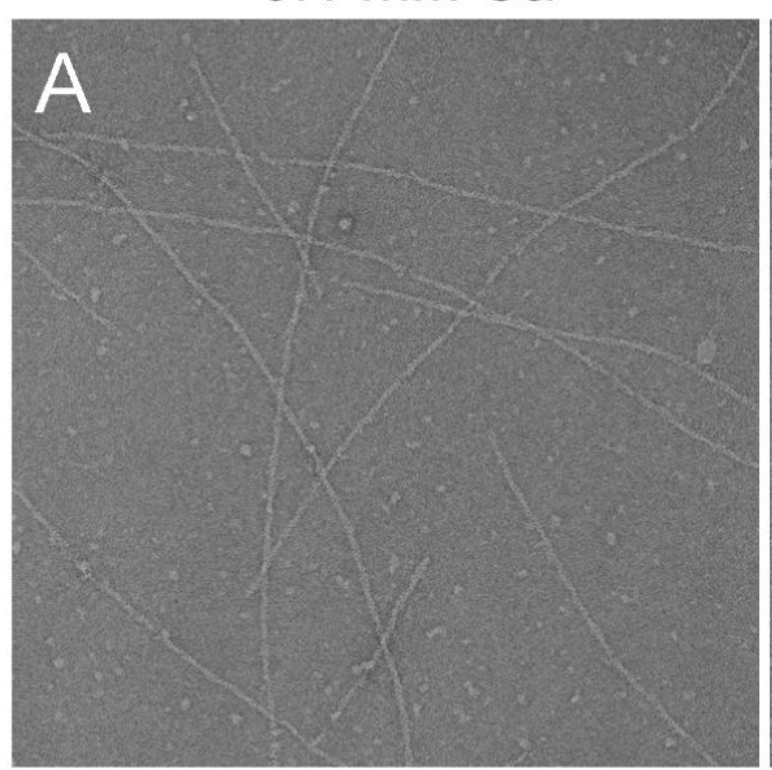

$5.0 \mathrm{mM} \mathrm{Ca}^{2+}$
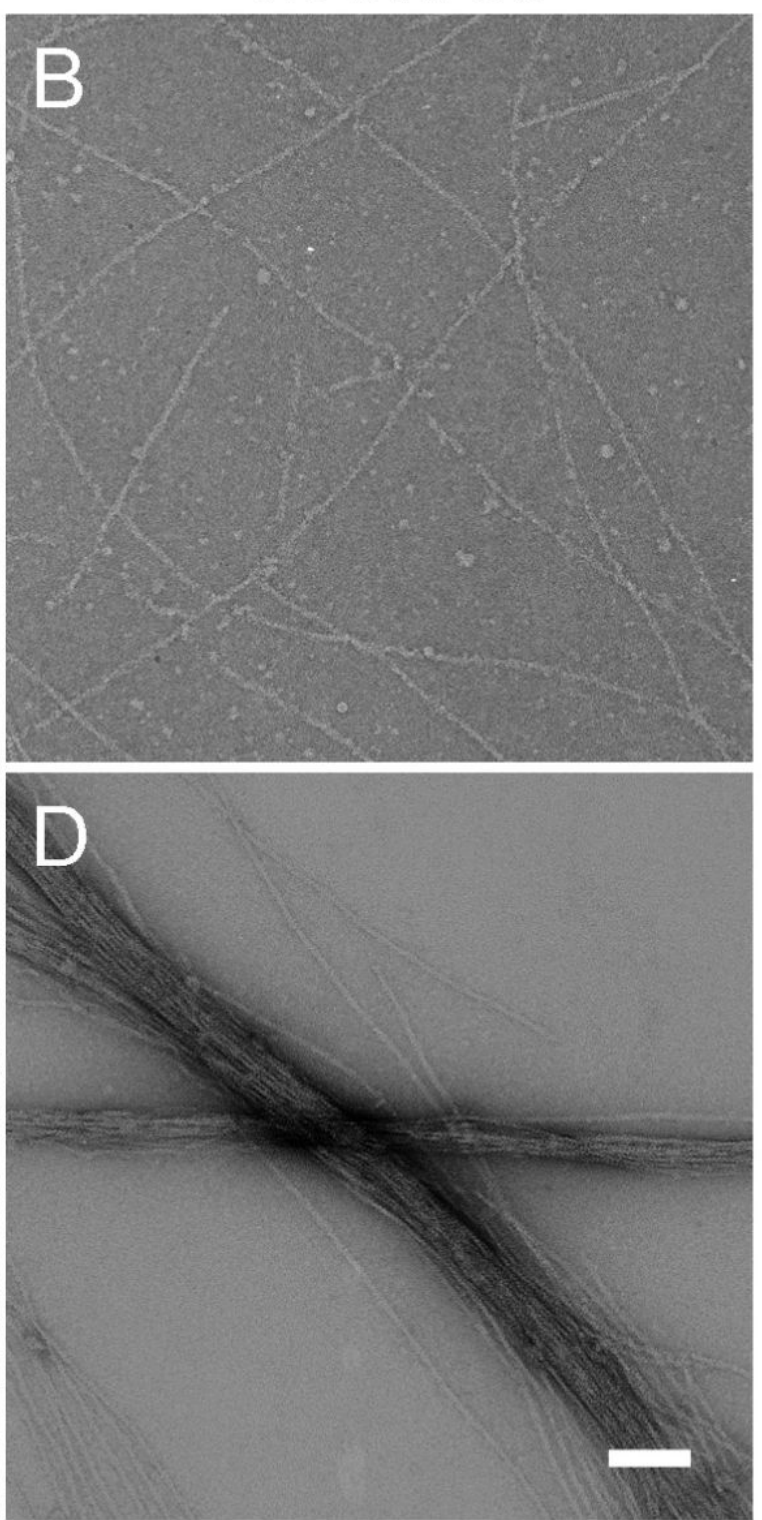

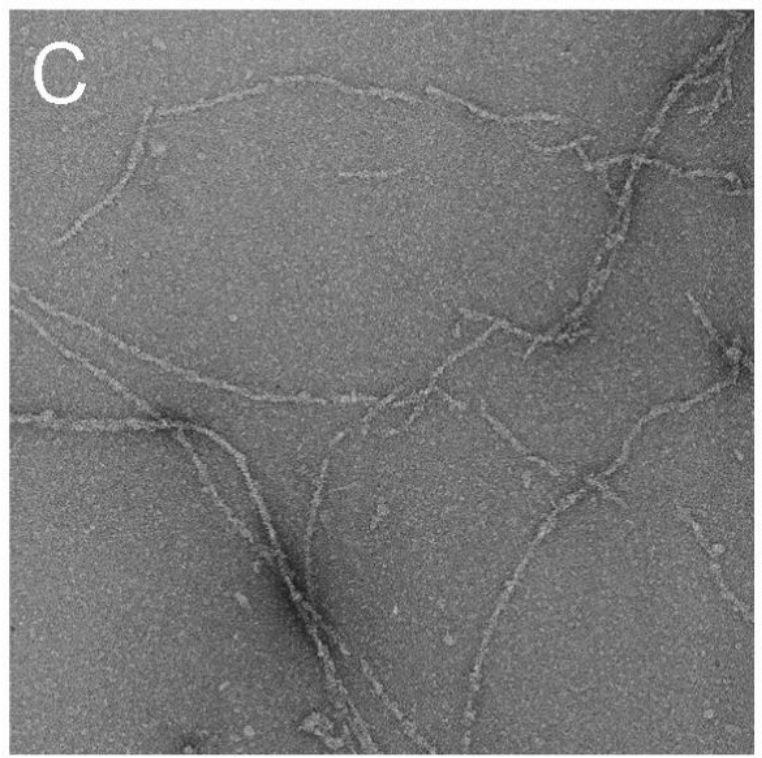

Figure 6.

Negative stain electron micrographs of calcium-sensitive F-actin bundling by D6-HP. A) Factin filaments $(1 \mu \mathrm{M})$ in the presence of $0.1 \mathrm{mM}$ calcium. B) F-actin filaments $(1 \mu \mathrm{M})$ in the presence of $5 \mathrm{mM}$ calcium. C) F-actin filaments with D6-HP in $0.1 \mathrm{mM}$ calcium. D) F-actin bundles with D6-HP in $5 \mathrm{mM}$ calcium. D6-HP and F-actin were both $5 \mu \mathrm{M}$ in experiments $\mathrm{C}$ and D. Samples were incubated at $4^{\circ} \mathrm{C}$ for 45 minutes and negatively stained with $1 \%$ uranyl acetate. Images were recorded by transmission electron microscopy at 45,000 $\times$ magnification. The magnification bar (on D) is $100 \mathrm{~nm}$ for all the images. 